\title{
Staff and student experiences and attitudes towards smoking and smoking cessation, University of Jeddah, Saudi Arabia
}

\author{
Mansour Tobaiqy', Dennis Thomas², Andrew MacLure', Derek Stewart ${ }^{4}$, Katie MacLure $^{5}$
}

\begin{abstract}
INTRODUCTION Tobacco smoking causes an estimated 7 million deaths per annum with 70 thousand of those occurring in the Kingdom of Saudi Arabia (KSA) where the National Transformation Program highlights the need to prioritize smoking cessation. The objective of this study was to determine the experiences and attitudes of university staff and students, who have been or are currently smokers, towards smoking and smoking cessation.

METHODS A link to a cross-sectional online survey was distributed by email in October and November 2020 to students and staff $(n=34872)$ at the University of Jeddah, KSA. The survey was based on WHO GATS, CSS-21 and a systematic review. Data were analyzed using descriptive statistics in JASP (version 0.14.1) [Computer software].

RESULTS A total of 666 responses were collected. Most respondents had never smoked $(n=556 ; 83.5 \%)$ with some current smokers $(n=72 ; 10.8 \%)$ and few former smokers $(\mathrm{n}=12 ; 1.8 \%)$. Major challenges of quitting smoking identified by the CSS-21 tool were intrinsic factors such as 'withdrawal symptoms' ( $\mathrm{n}=28$; $37.8 \%$ ), 'being addicted to cigarettes' ( $\mathrm{n}=24 ; 34.8 \%$ ), 'having strong emotions or feelings' ( $n=28 ; 38.4 \%)$, and 'seeing things or people which reminded me' $(n=25$; $34.2 \%)$. The extrinsic factors were mostly reported as 'not a challenge', such as 'use of other substances like cannabis, alcohol, etc.' ( $n=60 ; 87.0 \%)$ or 'lack of support or encouragement from health professionals to stop smoking' ( $\mathrm{n}=50$; $69.4 \%$ ). Many staff and students were 'asked if you smoked tobacco products' at a healthcare professional appointment with $(n=5 ; 83.3 \%)$ and $(n=27 ; 71.1 \%)$, respectively. Both staff $(n=6 ; 75.0 \%)$ and students $(n=19 ; 34.5 \%)$ thought 'faceto-face counselling' would help support their future attempts to quit.

CONCLUSIONS The majority of smokers who participated saw intrinsic factors more of a challenge than extrinsic factors. This new knowledge has the potential to influence decision makers. There is potential for encouraging healthcare practitioners to promote smoking cessation conversations.
\end{abstract}

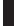

AFFILIATION

1 Department of Pharmacology, College of Medicine, University of Jeddah, Jeddah, Saudi Arabia 2 School of Medicine and Public Health, College of Health, Medicine and Wellbeing, University of Newcastle, Australia

3 Independent Researcher, Aberdeen, United Kingdom 4 College of Pharmacy, QU Health, Qatar University, Doha, Qatar 5 Independent Research Consultant, Aberdeen, United Kingdom

CORRESPONDENCE TO Mansour Tobaiqy. Department of Pharmacology, College of Medicine, University of Jeddah, 21512 Jeddah, Saudi Arabia. E-mail: mtobaiqy@ uj.edu.sa ORCID ID: https://orcid. org/0000-0002-4292-0900

\section{KEYWORDS}

smoking cessation, smoking, university students, university staff, quit smoking, Saudi Arabia

Received: 26 September 2021 Revised: 22 November 2021 Accepted: 23 November 2021

\section{INTRODUCTION}

Cigarette smoking is one of the leading causes of preventable morbidity and mortality globally and represents a key risk factor for cardiovascular diseases, stroke, and cancer ${ }^{1}$. The World Health Organization (WHO) engages with countries to adopt policies and strategies that encourage and support people to quit smoking ${ }^{1,2}$. However, to date, only 23 countries were on track before the global COVID-19 pandemic to meet the target and the Kingdom of Saudi Arabia (KSA) is not on this list ${ }^{2}$. A recent review reported that, of the 7 million smoking associated deaths occurring per annum worldwide, over 70 thousand are from KSA, underlining the 
importance of additional effective smoking control strategies in $\mathrm{KSA}^{3}$. Another recent systematic review which evaluated the attitudes of smokers and nonsmokers towards smoking cessation in $\mathrm{KSA}^{4}$, noted that despite strong Saudi Ministry of Health support for education programs that try to prevent the uptake of smoking, policy-driven action to reduce environmental secondhand smoking, and provision of support for smoking cessation, the problems remain ${ }^{3-8}$. Understanding people's attitudes and experiences of smoking is important to develop effective preventative strategies $^{9-12}$. Moreover, knowledge about previous quitting experiences and preferences for future quit attempts can help to optimize smoking cessation interventions ${ }^{3,13}$.

This study aimed to determine the experiences and attitudes of smokers and former smokers amongst University of Jeddah staff and students to smoking cessation.

\section{METHODS}

\section{Study design}

The survey instrument was an online survey using a pretested, structured questionnaire. Data were collected using a 29-item questionnaire. The questionnaire's content was based on WHO GATS (Global Adult Tobacco Survey), a tool called CSS-21 (Challenges to Stopping Smoking) and a systematic review that identified validated and non-validated tools and shortcomings of previous studies with recommendations ${ }^{3,4,13}$. It was reviewed for face and content validity using the 'Think Aloud' approach in which people are asked to verbalize their thought processes while completing the survey. The questionnaire was first developed in English and then translated and checked by back-translation to Arabic.

\section{Items in the survey}

Sociodemographic characteristics: smoking status, sex, nationality, marital status, age, student or university staff, household income; smoking exposure in the household and amongst friends, some of which is reported elsewhere alongside open text responses to a question on the impact of COVID-19 to smoking exposure ${ }^{9}$; current smoking methods and frequency; number of attempts to stop each method within the past 12 months; challenges to quitting smoking are assessed using CSS-2 ${ }^{13}$. CSS-2 1 considers two dimensions of challenges, either intrinsic (personal factors assessed using 9 items) or extrinsic factors (environmental factors assessed using 12 items) which may impact or influence a smoker's ability to quit smoking or the factors which might aid them in stopping smoking ${ }^{13}$. For each of the 21 items, the smoker is asked to mark on a scale choosing: 1 (not a challenge), 2 (minor challenge), 3 (moderate challenge), or 4 (major challenge).

\section{Setting and recruitment process}

The link to the questionnaire was distributed by email in October-November 2020 to students and staff at the University of Jeddah, KSA. The invitation explained the purpose of the survey, the voluntary nature of completion, and that responses were anonymized. English and Arabic languages were made available.

\section{Statistical analysis}

Responses were analyzed using descriptive statistics. Responses were downloaded to, and analyzed using, open source JASP (version 0.14.1) [Computer software].

\section{RESULTS}

The survey had been emailed to 34872 university members (2500 faculty, 1557 technician and administrative staff, and 30815 students) of which 666 people participated. The response rate was $1.9 \%$. The responses from current smokers and former smokers who had quit within the last 12 months $(n=84 / 666$; $12.6 \%)$ are reported here. Of these, there were 12 staff $(14.3 \%)$ who were current smokers with one $(1.2 \%)$ having quit within the previous 12 months. For students, 60 were current smokers $(71.4 \%)$ and $11(13.1 \%)$ having quit within the last year.

\section{Demographics}

The characteristics of all the current and former smokers are reported elsewhere ${ }^{9}$.

\section{Challenges to quitting smoking}

The CSS-21 tool, included in the survey, identified intrinsic and extrinsic factors (Table 1) impacting respondents smoking cessation attempts ${ }^{13}$. Responses were, to an extent, polarized; with each item either 'not a challenge' or a 'major challenge'. Major challenges on the intrinsic scale were "withdrawal symptoms' ( $n=28 / 74 ; 37.8 \%)$, 'being addicted 
to cigarettes' $(\mathrm{n}=24 / 69 ; 34.8 \%)$, 'having strong emotions or feelings' $(n=28 / 73 ; 38.4 \%)$, 'getting bored' ( $\mathrm{n}=29 / 74 ; 39.2 \%)$, 'seeing things or people which reminded me' $(\mathrm{n}=25 / 73 ; 34.2 \%)$, and the 'easy availability of cigarettes' which scored almost equally as both a major challenge $(n=28 / 75 ; 38.3 \%)$ and not a challenge $(n=29 / 75 ; 38.7 \%)$. By contrast, the extrinsic factors such as 'lack of support' $(n=50 / 72 ; 69.4 \%)$ or 'fear of side effects' ( $\mathrm{n}=37 / 72 ; 51.4 \%)$ were, for the most part, 'not a challenge' across the board. More items from the survey on the impact of COVID-19 on smokers and support for smoke-free zones are available in a separate research article ${ }^{9}$.

\section{Support for quitting smoking}

When asked about any healthcare provider advice or support offered during the previous 12 months (Table
2 ), few of the smokers or those who had stopped within the previous 12 months $(n=84)$ reported that they had been asked if they smoke tobacco $(n=32 / 84$; $38.1 \%)$ or use smokeless products $(n=5 / 84 ; 6.0 \%)$. Advice on quitting $(n=8 / 84 ; 9.5 \%)$ and referral to the smoking cessation clinic $(n=5 / 84 ; 6.0 \%)$ were minimal. In terms of support for current smokers to quit smoking ( $\mathrm{n}=72$; Table 2$)$, face-to-face counselling was the preferred method $(n=25 / 72 ; 34.7 \%)$, followed by access to an on campus mobile smoking cessation unit $(\mathrm{n}=18 / 72 ; 25 \%)$, medication $(\mathrm{n}=15 / 72 ; 20.8 \%)$, and using a mobile phone application $(n=10 / 72$; $13.9 \%$ ). Table 2 provides a more detailed breakdown in terms of university staff and students. It must be borne in mind that participants may not have had any healthcare provider consultations in the preceding year.

\section{Table 1. CSS-21 Intrinsic and extrinsic factors for quitting smoking ( $\mathbf{N}=\mathbf{8 4}$ )}

\begin{tabular}{|c|c|c|c|c|}
\hline Factors & $\begin{array}{c}\text { Not a } \\
\text { challenge } \\
n(\%)\end{array}$ & $\begin{array}{c}\text { Minor } \\
\text { challenge } \\
n(\%)\end{array}$ & $\begin{array}{c}\text { Moderate } \\
\text { challenge } \\
n(\%)\end{array}$ & $\begin{array}{c}\text { Major } \\
\text { challenge } \\
n(\%)\end{array}$ \\
\hline \multicolumn{5}{|l|}{ Intrinsic } \\
\hline $\begin{array}{l}\text { Withdrawal symptoms (e.g. depression, anxiety, restlessness, irritability, sleeplessness, } \\
\text { craving, etc.) }(n=74)\end{array}$ & $20(27.0)$ & $9(12.2)$ & $17(23.0)$ & $28(37.8)$ \\
\hline Feeling lost without cigarettes $(n=69)$ & $30(43.5)$ & $11(15.9)$ & $12(17.4)$ & $16(23.2)$ \\
\hline Being addicted to cigarettes $(n=69)$ & $22(31.9)$ & $12(17.4)$ & $11(15.9)$ & $24(34.8)$ \\
\hline $\begin{array}{l}\text { Having strong emotions or feelings such as anger, or feeling upset when I tried to stop } \\
\text { smoking }(n=73)\end{array}$ & $18(24.7)$ & $12(16.4)$ & $15(20.5)$ & $28(38.4)$ \\
\hline Something stressful happened when I was trying to stop smoking $(n=72)$ & $28(38.9)$ & $11(15.3)$ & $17(23.6)$ & $16(22.2)$ \\
\hline Thinking about never being able to smoke again after we stop smoking $(n=72)$ & $26(36.1)$ & $14(19.7)$ & $9(12.5)$ & $23(31.9)$ \\
\hline Getting bored when I was trying to stop smoking $(n=74)$ & $14(18.9)$ & $19(25.7)$ & $12(16.2)$ & $29(39.2)$ \\
\hline Seeing things or people which reminded me of smoking $(n=73)$ & $16(21.9)$ & $13(17.7)$ & $19(26.0)$ & $25(34.2)$ \\
\hline Easy availability of cigarettes $(n=75)$ & $29(38.7)$ & $9(12.0)$ & $9(12.0)$ & $28(37.3)$ \\
\hline \multicolumn{5}{|l|}{ Extrinsic } \\
\hline Difficulty in finding someone to help me to stop smoking $(n=71)$ & $43(60.6)$ & $12(16.9)$ & $9(12.7)$ & $7(9.9)$ \\
\hline Lack of support or encouragement from health professionals to stop smoking $(n=72)$ & $50(69.4)$ & $4(5.5)$ & $10(13.9)$ & $8(11.1)$ \\
\hline The cost of stop-smoking medicines such as nicotine replacement therapy $(n=73)$ & $42(57.5)$ & $8(11.0)$ & $12(16.4)$ & $11(15.1)$ \\
\hline Fear of side effects from stop-smoking medications $(n=72)$ & $37(51.4)$ & $8(11.1)$ & $13(18.1)$ & $14(19.4)$ \\
\hline Lack of encouragement or help from family or friends to stop smoking $(n=69)$ & $52(75.4)$ & $9(13.0)$ & $3(4.3)$ & $5(7.2)$ \\
\hline Fear of weight gain if I stopped smoking $(n=74)$ & $47(63.5)$ & $8(10.8)$ & $6(8.1)$ & $13(17.6)$ \\
\hline Family members or friends encouraging me to smoke $(n=70)$ & $53(75.7)$ & $5(7.1)$ & $6(8.6)$ & $6(8.6)$ \\
\hline Fear of failing to stop smoking $(n=71)$ & $35(49.3)$ & $11(15.5)$ & $8(11.3)$ & $17(23.9)$ \\
\hline Belief that medicines to stop smoking do not work $(n=71)$ & $42(59.2)$ & $14(19.7)$ & $8(11.3)$ & $7(9.9)$ \\
\hline Fear that stopping smoking may interrupt social relationships $(n=71)$ & $51(71.8)$ & $12(16.9)$ & $3(4.2)$ & $5(7.0)$ \\
\hline Belief that I can stop smoking in the future if I need to $(n=72)$ & $25(34.7)$ & $10(13.9)$ & $17(23.6)$ & $20(27.7)$ \\
\hline Use of other substances like cannabis, alcohol, etc. $(n=69)$ & $60(87.0)$ & $3(4.3)$ & $2(2.9)$ & $4(5.8)$ \\
\hline
\end{tabular}


Table 2. Healthcare provider influence ( $\mathbf{N}=84)$ and support options for quitting smoking $(\mathrm{N}=72)$

$\begin{array}{lcc}\text { During any visit to a healthcare provider in the last } 12 \text { months }(n=84) & \begin{array}{c}\text { Staff } \\ (n=6)\end{array} & \begin{array}{c}\text { Students } \\ (n=38) \\ n(\%)\end{array} \\ \text { Were you asked if you smoked tobacco products } & 5(\%) & 27(71.1) \\ \text { Were you asked to quit smoking tobacco products } & 3(50.0) & 12(31.6) \\ \text { Were you asked if you use smokeless products } & 1(16.7) & 4(10.5) \\ \text { Were you advised to quit smokeless products } & 1(16.7) & 0(0.0) \\ \text { Were you offered advice on quitting } & 3(50.0) & 5(13.2) \\ \text { Were you offered an appointment at a smoking cessation clinic } & 2(33.3) & 3(7.9) \\ \text { Thinking about possible support options for your future attempts to quit smoking, which of the } & \text { Staff } & \text { Students } \\ \text { following might help you (n=72) } & (n=8) & (n=5.5) \\ & n(\%) & n(\%) \\ \text { Face-to-face counselling } & 6(75.0) & 19(34.5) \\ \text { Access to an on-campus mobile smoking cessation unit } & 2(25.0) & 16(29.1) \\ \text { Telephone counselling } & 0(0.0) & 8(14.5) \\ \text { Text messages } & 0(0.0) & 10(18.2) \\ \text { Mobile phone app } & 0(0.0) & 12(21.8) \\ \text { Online resources } & 0(0.0) & 1(1.8) \\ \text { Medication } & 3(37.5) & 12(21.8) \\ \text { Support group face-to-face } & 0(0.0) & 0(0.0) \\ \text { Support group online } & 0(0.0) & 9(16.4) \\ \text { Alternative treatments such as hypnotherapy or acupuncture } & 2(25.0) & 5(9.1) \\ \text { Other } & 0(0.0) & 2(3.6)\end{array}$

\section{DISCUSSION}

Albeit hampered by a low response rate, the majority of smokers who participated in this study started tobacco use at an early age and have subsequently tried to quit multiple times without success. The CSS-21 tool results based on intrinsic and extrinsic factors, were arguably the most interesting to report ${ }^{13}$. None of the extrinsic factors was considered a major challenge, which might lead policy makers and support service designers to consider focusing on the intrinsic factors ${ }^{2,4,5-8}$. Amongst these, the key factors were: withdrawal symptoms, addiction, emotional reactions, smoking out of boredom, seeing reminders of smoking and ease of availability of cigarettes ${ }^{13}$. Many of these were identified in a recent systematic review $^{4}$.

The support from health professionals was disappointingly low and should be seen as a missed opportunity. Smokers amongst staff and students identified various methods to assist their future quit attempts with the majority preferring face-to-face counselling. The findings of this study are in line with prior research identified in a recently published systematic review, also by the authors of this study, in terms of: prevalence of smoking, age of starting smoking, exposure to smoking, intention to quit and quit attempts, methods and supports for smoking cessation $^{4}$.

Ministry of Health education programs in Saudi Arabia have long targeted young people with a view to preventing them from taking up smoking ${ }^{5-8}$. Consideration should be given to peer-education, participatory action research or co-design methods for creating anti-smoking campaigns empowering school-age children to get involved. This approach has recently been shown to be successful in other countries and may help to support the stated preference of both staff and students for face-to-face counselling ${ }^{14,15}$.

\section{Limitations}

Although the survey content was thoroughly 
researched and based on a published systematic review and tools from WHO GATS and CSS-21, recruitment to this study failed to reach an adequate response rate $^{3,4,13}$. This had been identified as a potential risk factor ${ }^{4}$. The survey was of course on a sensitive subject, lengthy to complete, and conducted during the global COVID-19 pandemic. Students had not returned to campus and many of the target population would have been distracted by ongoing events. This prevented the contingency option of circulating a paper-based survey or promoting the survey where people would gather socially. The low response rate meant inferential statistics would not be either meaningful or generalizable. There is always the chance of recall or acquiescence bias in self-reported surveys, so the results should be treated with caution.

\section{CONCLUSIONS}

Recommendations to focus on cigarette smoking prevention are: think in terms of helping groups of people, such as university staff and university students rather than individuals, to stop smoking; and consider methods with young people in co-creation of measures. There is potential for encouraging or incentivizing healthcare practitioners to further promote smoking cessation conversations and focusing on the intrinsic factors which are the major challenges for smokers who want to quit.

\section{REFERENCES}

1. World Health Organization. WHO Report on the Global Tobacco Epidemic, 2019: Offer help to quit tobacco use. World Health Organization; 2019. Accessed November 22, 2021. https://apps.who.int/iris/bitstream/hand le/10665/326043/9789241516204-eng.pdf

2. Good country practices in the implementation of WHO FCTC Article 14 and its guidelines. Secretariat of the WHO Framework Convention on Tobacco Control and the Protocol to Eliminate Illicit Trade in Tobacco Products; 2019. Accessed November 22, 2021. https://www.who. int/fctc/implementation/Good-country-practices-in-theimplementation-of-article-14.pdf

3. Asma S, Mackay J, Song SY, et al. The GATS Atlas: Global Adult Tobacco Survey. CDC Foundation; 2015. Accessed November 22, 2021. http://gatsatlas.org/downloads/ GATS-whole-book-12.pdf

4. Tobaiqy M, Thomas D, MacLure A, MacLure K. Smokers' and Non-Smokers' Attitudes towards Smoking Cessation in Saudi Arabia: A Systematic Review. Int J Environ Res Public Health. 2020;17(21):8194. doi:10.3390/ijerph17218194

5. National Transformation Program 2020. Vision2030.gov. sa. Accessed November 22, 2021. https://web.archive. org/web/20190101010207/https://vision2030.gov.sa/ sites/default/files/NTP_En.pdf

6. ANTI-SMOKING LAW Issued by Royal Decree No. (M/56) dated 28/07/1436 H: Implementing Regulations Version 3, 2019. Saudi Arabia Ministry of Health; 2019. Accessed November 22, 2021. https://www.moh.gov.sa/ en/Ministry/Rules/Documents/Anti-Tobacco-ExecutiveRegulations.pdf

7. Decision of the Minister of Health No 1853515 on 29/12/1439 AH: Approval on the Amendment of the Executive Regulation of Tobacco Control Law. Saudi Arabia Ministry of Health; 2018. Accessed November 22, 2021. https://www.tobaccocontrollaws.org/files/live/ Saudi\%20Arabia/Saudi\%20Arabia\%20-\%20Amdts. $\% 20$ to $\% 20$ Exec.\%20Regs.pdf

8. Itumalla R, Aldhmadi B. Combating tobacco use in Saudi Arabia: a review of recent initiatives. East Mediterr Health J. 2020;26(7):858-863. doi:10.26719/emhj.20.019

9. Tobaiqy M, MacLure A, Thomas D, MacLure K. The Impact of COVID-19 on Smoking Behaviours and Support for Smoke-Free Zones in Saudi Arabia. Int J Environ Res Public Health. 2021;18(13):6927. doi:10.3390/ijerph18136927

10. Park MB. Living with parents who smoke predicts levels of toxicant exposure in children. Sci Rep. 2020;10(1):11173. doi:10.1038/s41598-020-66920-y

11. Secondhand Smoke (SHS) Facts. Centers for Disease Control and Prevention. Updated January 5, 2021. Accessed November 22, 2021. https://www.cdc.gov/ tobacco/data_statistics/fact_sheets/secondhand_smoke/ general_facts/index.htm

12. Gentzke AS, Wang TW, Marynak KL, Trivers KF, King BA. Exposure to Secondhand Smoke and Secondhand E-Cigarette Aerosol Among Middle and High School Students. Prev Chronic Dis. 2019;16:E42. doi:10.5888/pcd16.180531

13. Thomas D, Mackinnon AJ, Bonevski B, et al. Development and validation of a 21-item challenges to stopping smoking (CSS-21) scale. BMJ Open. 2016;6(3):e011265. doi:10.1136/bmjopen-2016-011265

14. Bilgiç N, Günay T. Evaluation of effectiveness of peer education on smoking behavior among high school students. Saudi Med J. 2018;39(1):74-80. doi:10.15537/smj.2018.1.21774

15. Dobbie F, Purves R, McKell J, et al. Implementation of a peer-led school based smoking prevention programme: a mixed methods process evaluation. BMC Public Health. 2019;19(1):742. doi:10.1186/s12889-019-7112-7 
CONFLICTS OF INTEREST

The authors have completed and submitted the ICMJE Form for Disclosure of Potential Conflicts of Interest and none was reported.

\section{FUNDING}

This research was funded by University of Jeddah, Deanship of Scientific Research, Under International Collaborative Research Program (Contract Number: UJ-02-001-ICGR).

ETHICAL APPROVAL AND INFORMED CONSENT

Ethical approval was obtained from the Bioethics Committee for Scientific and Medical Research at the University of Jeddah (UJ-REC-002; 3 April 2020).

DATA AVAILABILITY

The data supporting this research are available from the authors on reasonable request.

\section{AUTHORS' CONTRIBUTIONS}

MT conceived the study and secured the funding. MT, KM, AM and DT designed and conducted the research, analyzed and interpreted the data. KM and MT wrote the initial draft of the article. DS conducted a critical review providing key insights. All authors have reviewed, commented on drafts and approved the final draft and are responsible for the content and similarity index of the manuscript.

PROVENANCE AND PEER REVIEW

Not commissioned; externally peer reviewed. 